\title{
NUMERICAL ANALYSIS OF AIR FLOW PAST THE 2415-3S AIRFOIL FOR AN UNMANNED AERIAL VEHICLE WITH INTERNAL PROPULSION SYSTEM
}

\author{
L. Velázquez-Araque ${ }^{1}$, Luis. D. Mendoza ${ }^{2}$, Jesús. Casanova ${ }^{3}$ and J. Nožička ${ }^{4}$ \\ ${ }^{1,2}$ Department of Mechanical Engineering, National University of Táchira, San Cristobal, Venezuela. \\ luis.velazquez@unet.edu.ve \\ ${ }^{3}$ Laboratory of Internal Combustion Engines, Universidad Politécnica de Madrid, Madrid, Spain. \\ ${ }^{4}$ Department of Mechanical Engineering, Czech Technical University in Prague, Prague, Czech Republic.
}

\begin{abstract}
This paper deals with the prediction of pressure and velocity fields on the $2415-3 \mathrm{~S}$ airfoil which will be used for and unmanned aerial vehicle with internal propulsion system and in this way analyze the air flow through an internal duct of the airfoil using computational fluid dynamics. The main objective is to evaluate the effect of the internal air flow past the airfoil and how this affects the aerodynamic performance by means of lift and drag forces. For this purpose, three different designs of the internal duct were studied; starting from the base 2415-3S airfoil developed in previous investigation, basing on the hypothesis of decreasing the flow separation produced when the propulsive airflow merges the external flow, and in this way obtaining the best configuration. For that purpose, an exhaustive study of the mesh sensitivity was performed. It was used a non-structured mesh since the computational domain is tridimensional and complex. The selected mesh contains approximately 12.5 million elements. Both the computational domain and the numerical solution were made with commercial CAD and CFD software respectively. Air, incompressible and steady was analyzed. The boundary conditions are in concordance with experimental setup in the AF 6109 wind tunnel. The $k-\varepsilon$ model is utilized to describe the turbulent flow process as followed in references. Results allowed obtaining pressure and velocity contours as well as lift and drag coefficients and also the location of separation and reattachment regions in some cases for zero degrees of angle of attack on the internal and external surfaces of the airfoil. Finally, the selection of the configuration with the best aerodynamic performance was made, selecting the option without curved baffles.
\end{abstract}

\section{INTRODUCTION}

According to the evolution of Unmanned Aerial Vehicles (UAV), several investments have been increasing every year, especially in the field of aerodynamic characteristics which can be obtained through wind tunnel tests.

This paper is part of a project which consists in the design of a solar UAV with internal blowing propulsion system; using computational fluid dynamics (CFD) on the 2415-3S airfoil, transport equations are aimed to be solved and also an accurate mesh refinement to obtain tridimensional velocity and pressure fields. The evaluation of the effect of the air flow through and past the airfoil on the aerodynamic behavior is one of the objectives of this paper; this air flow in actual conditions will be generated by a ducted fan located in the fuselage of the UAV. The analysis involved the comparison of two configurations of the internal design of the airfoil: with and without curved baffles. Another important result will be the numerical flow visualization by means of tridimensional streamlines. The whole process is described in the following sections.

\section{OVERVIEW OF THE ANALISYS MODEL}

The aim of this research is to analyze the behavior of the air flow at the internal cavity of the 2415-3S airfoil and predict possible zones of flow separation at the suction surface of this airfoil. A tridimensional numerical simulation by using CFD will be performed to obtain pressure and velocity fields and also streamlines of the flow.

\section{AIRFOIL TESTED}

The 2415-3S airfoil has been designed for the UAV focusing on several parameters of common commercial UAV's manufactures such as total wingspan, weight, flight velocity and others. It comes from a NACA four digits family airfoil, the NACA 2415 (Figure 1). It has an abrupt step on the suction side, located at $30 \%$ of the chord from the leading edge. This step simulates the blowing propulsive outlet of the wing in normal flight conditions. 


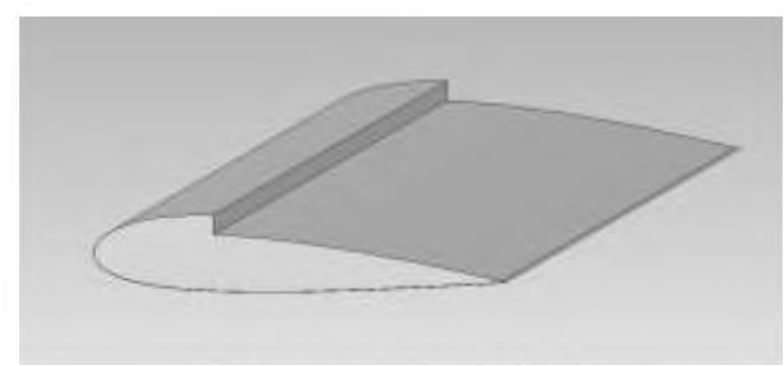

Figure 1. 2415-3S Airfoil

In a previous investigation [1] a two-dimensional numerical solution of the flow field past the 2415-3S was obtained as seen in Figure 2.

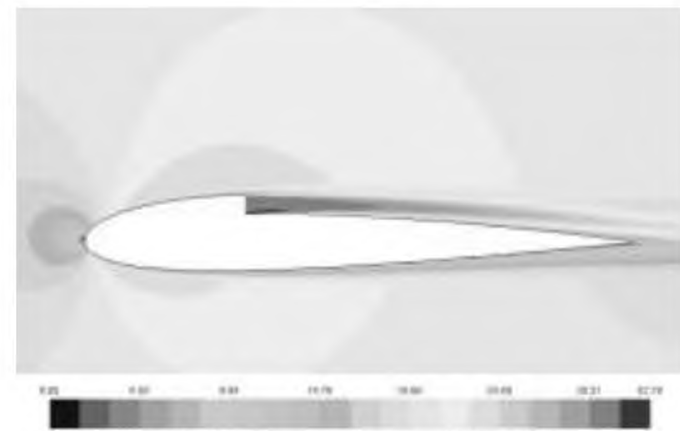

Figure 2. Velocity contours of the 2D numerical simulation of the 2415-3S airfoil at $0^{\circ}$ of angle of attack (AOA) [2]

It is possible to observe in Figure 2 the zone of highest velocity just next to the step which simulates the propulsive outlet. No presence of regions with a velocity of $0 \mathrm{~m} / \mathrm{s}$ besides the stagnation point at the leading edge, therefore no regions of separation were observed. Now the purpose is to validate those results with a tridimensional numerical simulation and also including the analysis of the flow through the internal cavity of this airfoil because that is how the air will be supplied to the wings in the actual situation. For this purpose, an exhaustive analysis of two configurations of the internal cavity is performed.

Below, it is possible to see two configurations of the airfoil's internal cavity. In Figure 3, a smooth rounded cavity outlet is shown (model A); this shape is intended to smooth the flow that comes from the ducted fan. Then, Figure 4 shows a cavity with a straight outlet (model B); this shape is intended to lead the flow tangential to the airfoil's suction surface.

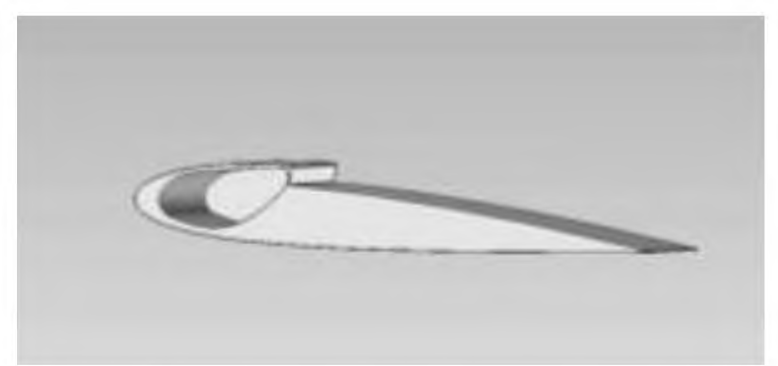

Figure 3. 2415-3S airfoil with a smooth rounded cavity outlet (model A)

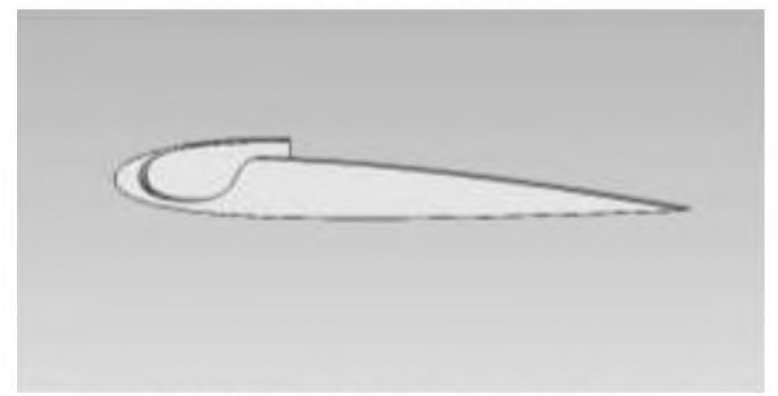

Figure 4. 2415-3S airfoil with a smooth straight cavity outlet (model B)

\section{COMPUTATIONAL DOMAIN}

Something very important in this part is the choice of the domain, because it is formed by real borders such as the upper and lower surfaces of the airfoil and also by imaginary borders which enclose the external environment [4]. A virtual wind tunnel was made to enclose the airfoil as seen in Figure 5. The domain extends from 1 chord lengths upstream to 5 chord lengths downstream also 1 chord lengths above and below the airfoil, having a width of 2 chord lengths; these dimensions are based on the actual wind tunnel AF 6109 located at the aerodynamics Laboratory at the University of Tachira.

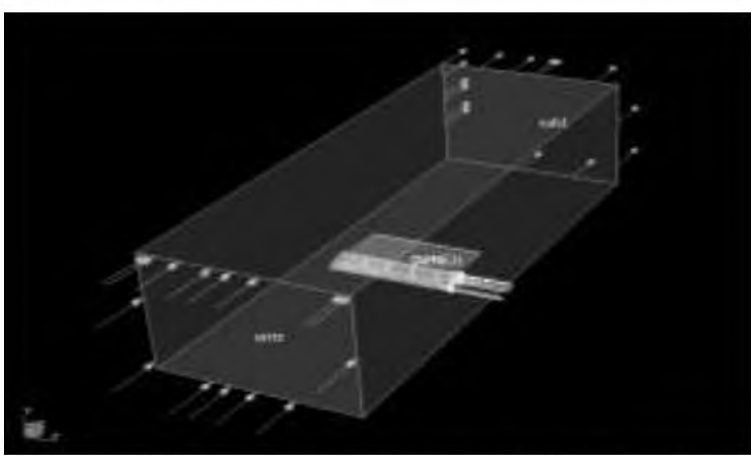

Figure 5: Computational domain for the numerical simulations 


\section{DISCRETIZATION OF THE DOMAIN}

The geometry shown in Figure 5 is discretized using an unstructured mesh of approximately 12.5 million elements after performing a mesh sensitivity study; this mesh has been also supplemented with very small elements in the vicinity of the surface of the airfoil forming a boundary layer. References when creating the mesh were followed [3]. The domain was created by using commercial CAD software and the mesh was created by using commercial CFD software as seen in Figure 6. Single meshes were created for each internal cavity configuration.

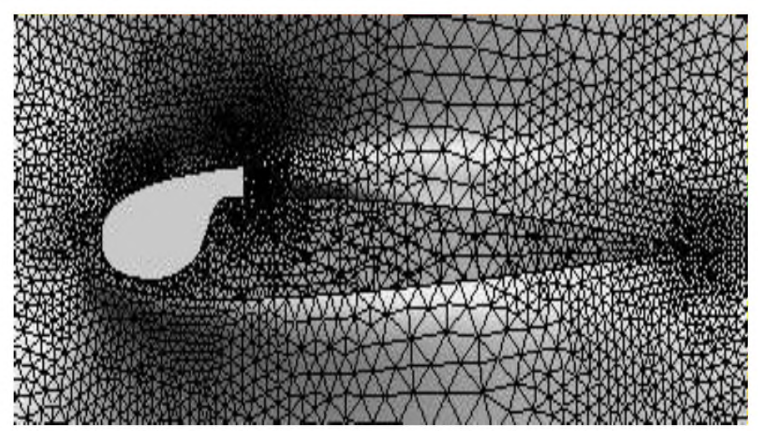

Figure 6: A mesh used for the numerical simulation

The complexity of the 2415-3S airfoil's internal cavity turns the meshing process complex as well since very small volumes or cells are generated and thus increasing the mesh density and then the computing time.

\section{BOUNDARY CONDITIONS}

At the inlet of the tunnel, it is specified the air absolute velocity magnitude of $20 \mathrm{~m} / \mathrm{s}$ and also its components; in this case the velocity is parallel to the horizontal axis; therefore it does not have any component in the ordinates. Likewise, at the inlet of the airfoil's internal cavity, air absolute velocity magnitude of $20 \mathrm{~m} / \mathrm{s}$ was set. The upper and lower surfaces of the airfoil are set as walls. At the outlet it is specified the pressure as the atmospheric pressure. For the lateral walls of the domain they are set as symmetry.

\section{TURBULENCE MODEL}

The $k-\varepsilon$ model is derived from the Navier-Stokes equations and it is one of the simplest complete models of turbulence with two-equation models in which the solution of two separate transport equations allows the turbulent velocity and length scales to be independently determined. The standard $k-\varepsilon$ model in falls within this class of models and has become very used for practical engineering flow calculations. It is a semi-empirical model. It is robust, economic, and presents reasonable accuracy for a wide range of turbulent flows.

\section{RESULTS AND ANALYSIS}

Air at $25^{\circ} \mathrm{C}$, incompressible and stationary is simulated with a Reynolds number of $2 \times 10^{5}$. In Figures 7 and 8 it is possible to see the air flow behavior at the internal cavity of the 2415-3S airfoil by means of streamlines.

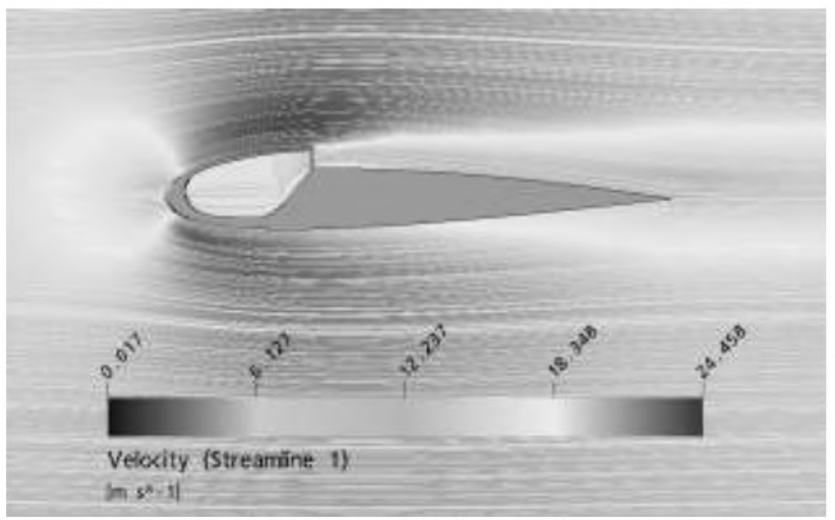

Figure 7. Flow streamlines past model A (rounded cavity outlet)

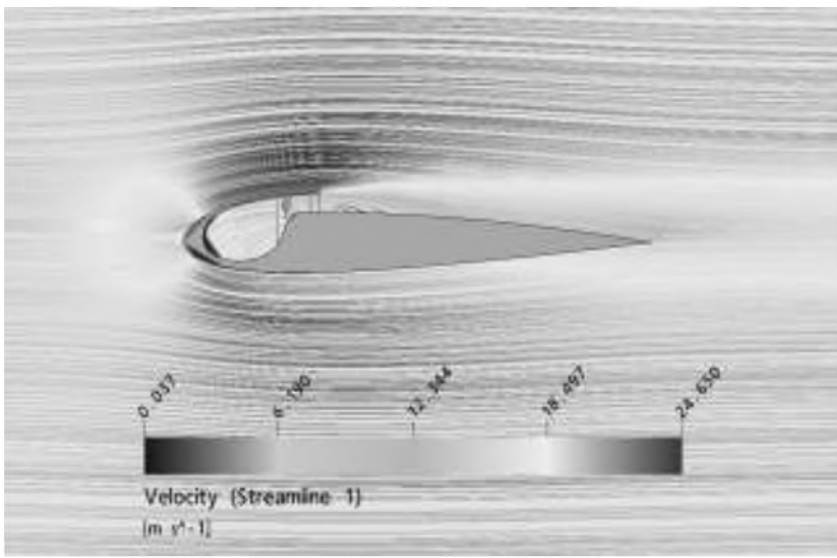

Figure 8. Flow streamlines past model B (straight cavity outlet)

It is possible to observe in Figure 7 that the cavity with a rounded outlet (model A) although it increases the forced air flow inlet area, tends to produce certain separation due to its curvature. Figure 8 shows that the cavity with a straight outlet (model B) produces less separation of flow in a small degree which enhances the airfoil's aerodynamic behavior. Therefore this model was chosen.

Below, Figures 9 and 10 show the velocity field and streamlines along the whole 2415-3S airfoil's suction surface. 


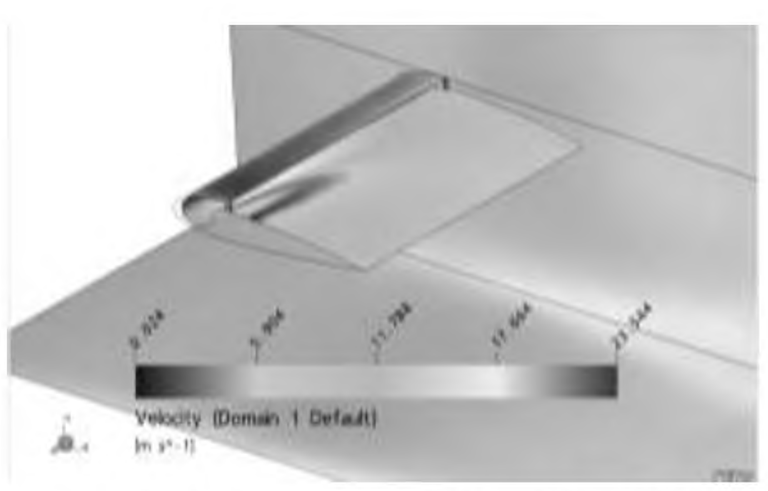

Figure 9. Surface velocity field past the 2415-3S airfoil (model B)

In Figure 9 it is possible to see that the air flow is attached to almost the whole airfoil's suction surface, however there is a zone where the velocity is very close to $0 \mathrm{~m} / \mathrm{s}$ which may indicate that the flow is probably detached and may lead to a separation region.

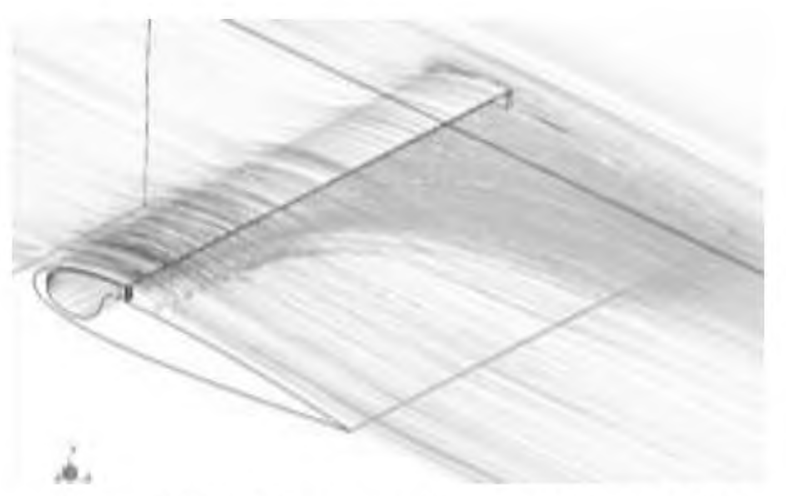

Figure 10. Air flow streamlines past the 2415-3S airfoil (model B)

Air flow streamlines in Figure 10 are now confirming that there is a separation region close to the airfoil's forced air inlet. Inside this region, it is possible to observe that the adverse pressure gradient causes a reversed flow and this becomes into a counter-rotating vortex.

Starting from this model, a baffle was placed inside the internal cavity of model $\mathrm{B}$ in order to redirect the forced air flow to minimize the flow separation on the suction surface; in this configuration, the baffle was placed halfway the span leading to model $\mathrm{C}$. It is important to mention that making this new configuration, the meshing process is even more complex increasing the computing time.
Below, Figures 11 and 12 show the velocity field and streamlines along the 2415-3S airfoil's suction surface with the internal baffle.

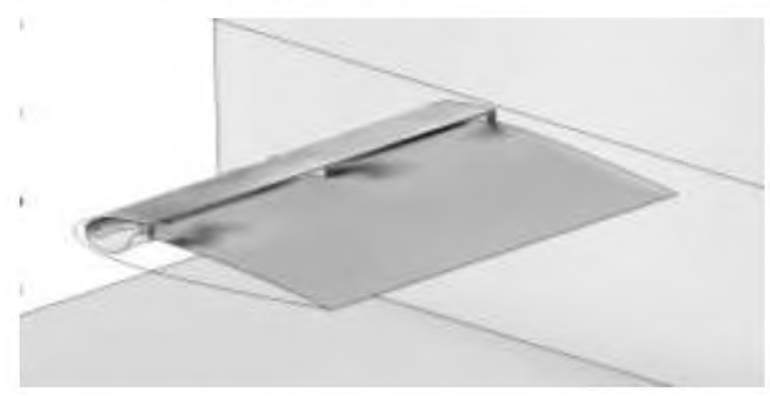

Figure 11. Surface velocity field past the 2415-3S airfoil (model C)

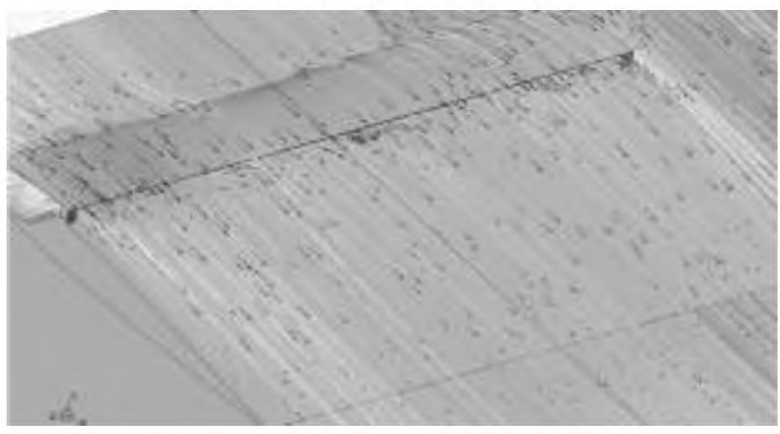

Figure 12. Air flow streamlines past the 2415-3S airfoil (model C)

Figure 11 shows the presence of certain zones of flow separation (deep blue color). Observing Figure 12 , it is possible to notice that the internal baffle also generates certain recirculation. The force air flow tends to return due to the pressure drop that the rest of the flow provokes when passing along the baffle at the internal cavity.

In order to develop another feasible solution, model $\mathrm{C}$ was modified placing three curved baffles in an equidistant array and smaller than the one used in model $\mathrm{C}$ as seen in Figure 13.

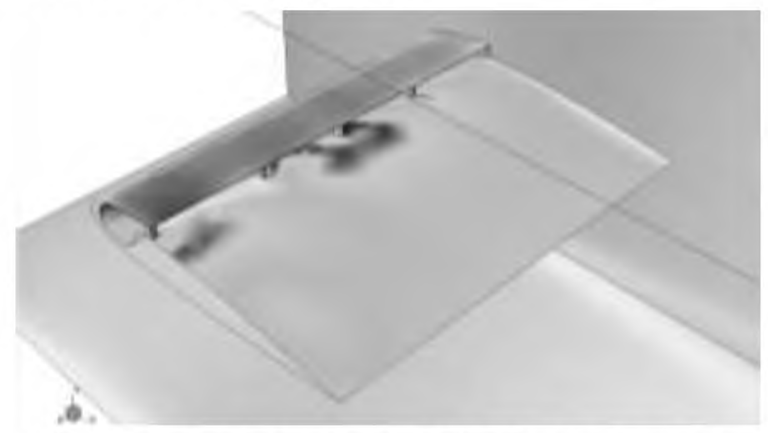

Figure 13: Surface velocity field past the 2415-3S airfoil (model D) 
Likewise the previous case, it is possible to observe that placing more baffles within the $2415-3 \mathrm{~S}$ airfoil's internal cavity, more recirculation and separation regions are obtained. This due to part of the flow that goes to the airfoil's surface tends to return at the outer edge of the baffle because of the pressure drop.

Finally a new internal design is introduced, without curved baffles but modifying the 2415-3S airfoil's internal cavity in such a way to redirect as best as it gets the forced air flow towards the suction surface and minimize the flow separation as shown in Figure 14.

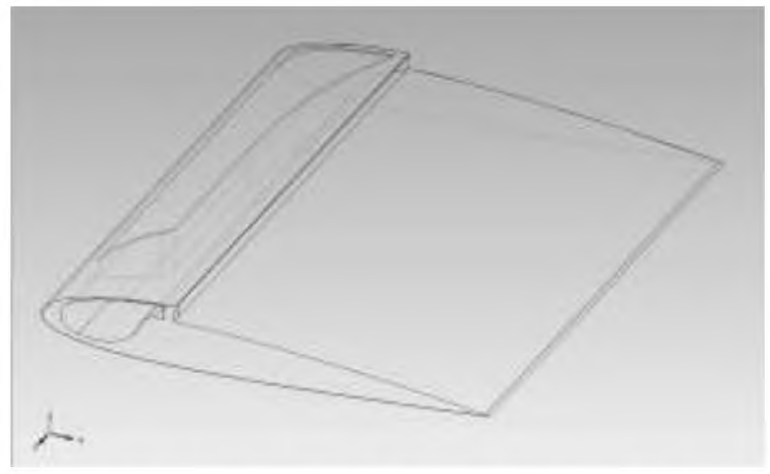

Figure 14. 2415-3S airfoil without internal curved baffles (model E)

In Figure 15 it is possible to see that the locations with the lowest velocity are smaller than the ones obtained with previous models. However it is still present. Therefore model $\mathrm{E}$ is the most adapted so far with respect to the other analyzed models because it is clear that this latter modification presents smaller separation regions on the $2415-3 \mathrm{~S}$ airfoil's suction surface.

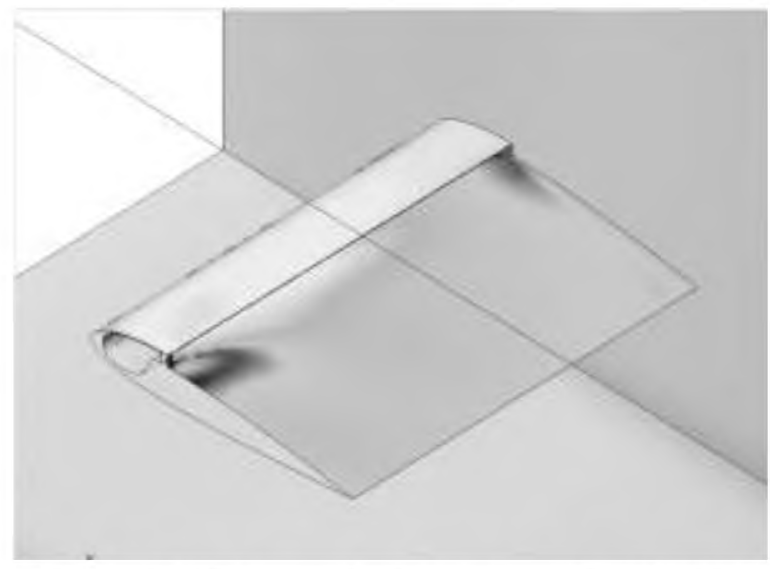

Figure 15. Surface velocity field past the 2415-3S airfoil (model E)

\section{CONCLUSION}

By means of the use of computational fluid dynamics it has been possible to obtain the flow field of air past and through the internal cavity of a new designed airfoil, the $2415-3 \mathrm{~S}$. It was also possible to obtain the location of separation regions in some cases. Four configurations were analyzed through an exhaustive comparison of the flow field by means of velocity contours and streamlines turning out that the aerodynamic performance of the configuration without internal curved baffles (model E) shows the best aerodynamic performance among the other three proposed configurations.

\section{FUTURE WORK}

Since this work is part of the development of the unmanned aerial vehicle with internal propulsion, a lot of work still needs to be done, however concerning airfoils, which was the scope of this work, new questions have been found according to obtained results and several aspects can be investigated focusing on:

- Obtaining numerical aerodynamic coefficients such as lift drag and pitching moment.

- Validation of numerical results by testing experimentally the selected 2415-3S airfoil configuration and study its aerodynamic performance in terms of the flow distribution for efficient propulsion.

\section{REFERENCES}

[1] Velazquez-Araque L. (2013): "Development of an Airfoil for an Unmanned Aerial Vehicle", LAP LAMBERT Academic Publishing ISBN13: 978-3659332623.

[2] Velazquez-Araque L., Nožička J (2012).: Numerical analysis of Flow past an Airfoil for a Solar Powered Unmanned Aerial Vehicle with Internal Propulsion System", Proceedings of The $23^{\text {rd }}$ International Symposium on Transport Phenomena. Auckland, New Zealand.

[3] Velazquez-Araque L., Nožička J.(2012): "Computational Simulation of the Flow past an Airfoil for an Unmanned Aerial Vehicle", Proceedings of The $5^{\text {th }}$ International MultiConference on Engineering and Technological Innovation: IMETI 2012. Orlando, USA.

[4] Jeandrevina G., Saccoa C., Paolettib C. and Preidikmanc S. "Simulación numérica utilizando CFD de los ensayos en túnel de viento de una pala de generador eólico en condición de operación rotor estático". 